\title{
Process for Setting Research Priorities: A Case Study from the State Networks of Colorado Ambulatory Practices and Partners (SNOCAP) Consortium
}

\author{
Mary Fisher, MPH, Sarah E. Brewer, MPA, Douglas H. Fernald, MA, \\ Jodi Summers Holtrop, PhD, Andrea Nederveld, MD, MPH, \\ Sean T. O'Leary, MD, MPH, Matthew Simpson, MD, MPH, \\ John M. Westfall, MD, MPH, Linda Zittleman, MSPH, and Donald E. Nease, Jr., MD
}

Purpose: It is important to share processes that practice-based research networks (PBRNs) can implement with PBRN members and partners to determine research topics of priority. Engaging partners at a preproject phase and continuing engagement throughout a project can help address topics of great need and increase meaningfulness at a local level.

Methods: The State Networks of Colorado Ambulatory Practices and Partners (SNOCAP) practicebased research network has a 20-year history of research topic prioritization. Annually, PBRN members and partners come together to set new priorities for SNOCAP to put focus on in the coming years. Methods from these Colorado PBRNs are shared as a framework for other PBRN networks, community and patient partners, and stakeholders to use.

Results: Engaging PBRN members and researchers in a bidirectional manner in preproject prioritization helps address current needs and gaps in care and identifies topics that are meaningful and important statewide. SNOCAP shares various approaches and lessons learned, provides guidance to PBRNs wanting to establish priorities, and helps guide groups that want to engage, or engage more deeply with, network members. Priority setting methods, a sample agenda, and resulting SNOCAP projects from the past 5 years of prioritization are shared.

Conclusions: Inquiry on a regular basis is an important step in practice- or community-based research. Getting to the local level to determine and fully address priority needs is not only "the right thing to do," rather, it is essential in true bidirectional work. (J Am Board Fam Med 2019;32:655-662.)

Keywords: Colorado, Community Medicine, Community Networks, Patient Participation, Practice-based Research, Primary Health Care

Primary care practice-based research networks (PBRNs) grew out of the grassroots concerns of clinicians who felt that research agendas and find-

This article was externally peer reviewed.

Submitted 25 January 2019; revised 30 May 2019; accepted 14 June 2019.

From University of Colorado, Department of Family Medicine, Aurora, CO (MF, SB, DHF, JSH, AN, MS, JMW, LZ, DEN); Adult and Child Consortium for Health Outcomes Research and Delivery Science, Aurora, CO (SB, STO, DEN); University of Colorado, Department of Pediatrics, Aurora, CO (STO).

Funding: none.

Conflict of interest: none declared.

Corresponding author: Mary Fisher, MPH, University of Colorado, Department of Family Medicine, Aurora, CO 80111 (E-mail: mary.fisher@cuanschutz.edu). ings from academic health centers rarely reflected the reality of community-based primary care practice. ${ }^{1,2}$ With the evolution of PBRN funding models, there is more reliance on federally funded research projects to sustain PBRN efforts, and thus this initial "bottom-up" research agenda has shifted toward the interests of funding agencies and academic health center researchers. ${ }^{3}$ Perhaps reflecting this bias, the 2015 publication titled Practicebased Research Network Research Good Practices (PRGPS): Summary of Recommendations ${ }^{4}$ describes steps in conducting PBRN research. In the first step, called the preproject phase, ${ }^{4}$ the 3 tasks are the following: (1) PBRN establishes a relationship with the project principal investigator, (2) project 
concept is developed with PBRN advice and involvement, and (3) the PBRN Advisory Board reviews and approves the project. Regular inquiry into the priorities and concerns of practices and their patients and communities is not mentioned in this preproject phase. Mold and Peterson ${ }^{5}$ recommended that PBRNs, "insist that clinicians play a major role in setting the agenda for PBRN activities. . " and cautioned member clinicians: "do not let the academicians take over your network." Therefore, to maintain the relevance of PBRN research to practices and the communities they serve, it is essential that PBRNs have routine, formal processes for eliciting and acting on the concerns of their partners. ${ }^{5,6}$ The need for input has been highlighted when PBRN members have been asked. $^{7}$

A 2018 literature review of patient and public engagement in priority setting finds that guidance on how to engage with and obtain patient and public perspective is lacking. Manafò et $\mathrm{al}^{8}$ find that engagement is usually done in 1 of 2 ways: deliberative or consultative engagement. Deliberative engagement describes the highest level of engagement where patients are equal or lead stakeholders in codeveloping topics with researchers, whereas consultative engagement is defined as patients acting as consultants or advisors only to topics that are important to them. Deliberative engagement is the style State Networks of Colorado Ambulatory Practices and Partners (SNOCAP) uses while engaging practices, patients, and communities in priority setting.

Literature from the community engagement field confirms that topics selected by practices, patients, and communities have more local perspective and may, therefore, be higher priority; from there, one can assume more robust engagement and, therefore, outcomes for projects addressing these community-defined needs. ${ }^{9-12}$ When a PBRN functions more like a grassroot organization, constituents, or in this case PBRN members, can work together to identify shared problems, work to find solutions, locate targets for possible solutions, and build capacity for future problems. ${ }^{13}$ Building on this foundation for relevant research may lead to sustainable change around important health topics. ${ }^{14}$ This shift can take hold if structures are put into place, such as partnering with PBRN members, when setting research priorities.
In this article, methods for how SNOCAP has formalized systematic approaches to identify and select health topics of priority are shared. The intent is to contribute to a set of PBRN best practices ${ }^{4}$ and to present additional approaches and lessons learned to enable other PBRNs to establish their own research priorities, engage with network members, and report progress to stakeholders.

\section{Methods}

SNOCAP, an umbrella network of Colorado PBRNs affiliated with the University of Colorado, currently includes 5 separate PBRN networks, each with their own staff and unique structures: Building InvestiGative practices for better Health Outcomes Research Network (BIGHORN), Colorado Research Network (CaReNet), Colorado Children's Outcomes Network (COCONet), High Plains Research Network (HPRN), and Partners Engaged in Achieving Change in Health Network (PEACHNet).

For over 20 years, SNOCAP has brought PBRN members together at an conference that gathers PBRN members, patient and community advisory group members, community engagement groups, and other PBRN partners. This conference is when priority topic conversations are started each year. There are 2 formats for this conference that alternate setting every other year. During even-numbered years, SNOCAP holds the conference in conjunction with the Colorado Area Health Education Centers. This conference is called Engaging Communities in Education and Research (ECER) ${ }^{15}$ and assembles around 500 attendees from practice-based research, rural preceptor sites, and rural residency programs across Colorado. Attendees also include members from all 5 SNOCAP PBRNs, patient and community advisory group members, and the Colorado Clinical and Translational Science Institute's Community Engagement (CCTSI-CE) staff and partners. During odd-numbered years, SNOCAP hosts a smaller conference called SNOCAP Convocation that brings together a more defined group of SNOCAP network members, patient and community advisory group members, and CCTSI-CE. SNOCAP Convocation welcomes approximately 130 practice, patient, and community partners, as well as a number of PBRN researchers to engage in conversations around PBRN work occurring across the state, share current and upcoming projects, and plan for future needs. 
Table 1. Methods for Priority Topic Generation and Facilitated Discussion at SNOCAP Priority Setting Sessions 2014 to 2018

\begin{tabular}{|c|c|c|c|}
\hline Year & $\begin{array}{c}\text { Phase 1: Source of Priority Topics for } \\
\text { Discussion }\end{array}$ & $\begin{array}{c}\text { Phase 2: Method of Facilitated } \\
\text { Discussion }\end{array}$ & Description \\
\hline \multirow[t]{2}{*}{2014} & $\begin{array}{l}\text { - Open-ended survey as a part of } \\
\text { registration to elicit topics. }\end{array}$ & $\begin{array}{l}\text { Small/Large Group Facilitated } \\
\text { Discussion }\end{array}$ & $\begin{array}{l}\text { - Small groups focused on three } \\
\text { topic areas with report outs to } \\
\text { large group. }\end{array}$ \\
\hline & $\begin{array}{l}\text { - SNOCAP leaders identified the top } \\
\text { three most common responses. }\end{array}$ & & \\
\hline \multirow[t]{3}{*}{2015} & $\begin{array}{l}\text { Open-ended survey as a part of } \\
\text { registration to elicit topics. }\end{array}$ & $\begin{array}{l}\text { Nominal Group Technique: stand/sit } \\
\text { to vote. Additional Large-Group } \\
\text { Facilitated Discussion }\end{array}$ & $\begin{array}{l}\text { - Facilitators had participants } \\
\text { vote to reduce number of } \\
\text { topics. }\end{array}$ \\
\hline & $\begin{array}{l}\text { - Small group of SNOCAP leaders } \\
\text { analyzed and brought forward } \\
\text { commonly identified topics. }\end{array}$ & & $\begin{array}{l}\text { Large-group discussion } \\
\text { developed action steps. }\end{array}$ \\
\hline & $\begin{array}{l}\text { - A Word Cloud was created to provide a } \\
\text { visual look at survey data. }\end{array}$ & & \\
\hline \multirow[t]{2}{*}{2016} & $\begin{array}{l}\text { - Open-ended geo-coded survey as a part } \\
\text { of registration or on day } 1 \text { of } \\
\text { conference to elicit topics. }\end{array}$ & $\begin{array}{l}\text { Nominal Group Technique: ranking } \\
\text { with sticky dots. Additionally, } \\
\text { arcGIS* Visual Mapping Discussion } \\
\text { plus Large-Group Facilitated } \\
\text { Discussion }\end{array}$ & $\begin{array}{l}\text { Day 1: Look at all topics, go } \\
\text { through GIS mapping, notes } \\
\text { of why each top concern was } \\
\text { an issue to discuss. }\end{array}$ \\
\hline & $\begin{array}{l}\text { - List of topics was created and organized } \\
\text { prior to first conference session. }\end{array}$ & & $\begin{array}{l}\text { - Day 2: Narrowed topics using } \\
\text { sticky dot method }\end{array}$ \\
\hline 2017 & $\begin{array}{l}\text { Participants responded to open-ended } \\
\text { survey pre-conference or on day } 1 \text { of } \\
\text { conference. Topics collated and } \\
\text { condensed to } 7 \text { based on frequency. }\end{array}$ & World Café ${ }^{16}$ & $\begin{array}{l}\text { - } 10 \text { small groups formed to } \\
\text { rotate around topic tables to } \\
\text { discuss, refine and develop } \\
\text { action steps for each. }\end{array}$ \\
\hline 2018 & $\begin{array}{l}\text { Open-ended surveys prior to ECER and } \\
\text { responses on poster on Friday. }\end{array}$ & $\begin{array}{l}\text { Liberating Structure: What, So What, } \\
\text { Now What }{ }^{17}\end{array}$ & $\begin{array}{l}\text { - Sticky dots used to narrow } \\
\text { topics. }\end{array}$ \\
\hline & & 18 & $\begin{array}{l}\text { - What, So What, Now What } \\
\text { facilitated discussion in small } \\
\text { groups. }\end{array}$ \\
\hline
\end{tabular}

*Environmental Systems Research Institute (ESRI) (2016). ArcGIS release 10.4 Redlands, CA.

SNOCAP, state networks of colorado ambulatory practices and partners consortium; ECER, engaging communities in education and research conference; GIS, geographic information system.

\section{Priority Setting}

Although priority setting has been on the agenda for 20 years, SNOCAP leadership and other partners have worked over the past 5 years to formalize structures for the prioritization process that culminates at either ECER or SNOCAP Convocation. Conference sessions on priority setting begin with SNOCAP leaders briefly reporting progress on the previous years' topics to demonstrate the impact of the process and accountability of the PBRN researchers, and to set the stage for new priorities to come. These sessions are used to solicit research and health priority topics of interest. After topics have been generated, discussions are led by trained facilitators to allow the group to develop a focused agenda. These discussions help focus in on the topics of highest priority for SNOCAP networks to address. Examples of methods SNOCAP has used to engage practice and community members in priority setting discussions are described in more detail in Table 1.

Each fall, SNOCAP members, including all conference participants, are sent an open-ended survey to list research or health topics of concern for their practice or community. SNOCAP has structured priority setting as such to be sure all voices are noted, not just those that attend the conference. Working together during the topic exploration stage helps identify topic priorities, as well as topic or practice champions. Finding topics of interest that someone at the practice can champion is an important outcome of these sessions. In addition, engaged priority setting facilitates future practice recruitment, as momentum around a particular topic can propel local engagement.

In both 2014 and 2015, after topics were narrowed by conference participants by means of a simple in-time vote, a small group of trained facil- 
itators led a large-group discussion to narrow focus and determine where gaps in care lie. The following year at the 2016 conference, a similar process was used; however, a geographic information system specialist was invited to work in real-time to overlay priority topics over a map of Colorado. This technique was used to determine in-the-moment how various areas within the state differed from topic to topic. During a monthly meeting of SNOCAP partners before the 2017 Convocation, meeting attendees reminisced that in previous years, many voices, mainly patient partners and community members, were going unheard in large group conversations. SNOCAP staff was then asked to review various methodologies for how to change the priority session for that year. While looking into this, and discussing with other colleagues, World Café arose as a new method to try. ${ }^{16}$ Briefly, World Café uses progressive, or advancing, rounds of small group conversation, where each group discusses for a brief time 1 topic, then moves to another conversation to build onto the foundation already built for the subsequent topic. This method was chosen as the engagement method for Convocation, and World Café "table hosts," or small group facilitators, were trained. During recap conversations and while reading evaluations, it was found that the structure of the World Café yielded too many topics, and SNOCAP leadership heard that people wanted to go deeper into the planning phase with selected topics. In 2018, before the state-wide ECER conference, SNOCAP leaders, researchers, and PBRN members began brainstorming new methods of facilitating conversations. Liberating Structures ${ }^{17}$ was suggested as a means to harness the collective power and knowledge of the entire group. Within Liberating Structures, the "what, so what, now what" method ${ }^{18}$ was chosen, which works progressively to figure out what the issue is, why it is an issue, and what to do next. This method helped take conversations a step further by splitting the large group into several small groups. Each small group was assigned 1 of the priority topics to work through the "what, so what, and now what." Results were shared with the large group, as well as with researchers who will work to bring these topics forward for future projects.

Using the discussion methods described above, sessions have been structured as 2- to 3-hour meetings, usually bringing together 45 to 90 stakehold-
Table 2. SNOCAP Priority Setting Session: Sample Agenda Template ( 2 hours, 45 minutes total)

\begin{tabular}{|c|c|}
\hline Time & Activity \\
\hline 30 minutes & $\begin{array}{l}\text { History of past years' priority topics (if } \\
\text { applicable). }\end{array}$ \\
\hline 10 minutes & $\begin{array}{l}\text { Share information about how priority topic } \\
\text { list was created. } \\
\text { This will be determined at the PBRN } \\
\text { level for how topics will be collected. }\end{array}$ \\
\hline \multirow[t]{6}{*}{20 minutes } & Narrow list of priority topics. \\
\hline & $\begin{array}{l}\text { - Gather all topics of priority in one list } \\
\text { (topics gathered via survey, GIS mapping, } \\
\text { in-person polling, etc., based on PBRN } \\
\text { preference). }\end{array}$ \\
\hline & $\begin{array}{l}\text { - All priority topics written on flip charts } \\
\text { around room. }\end{array}$ \\
\hline & $\begin{array}{l}\text { - Give each participant } 2 \text { colored dots, } \\
\text { instruct them to place their stickers on } \\
\text { their top } 2 \text { topics of priority. }\end{array}$ \\
\hline & $\begin{array}{l}\text { This will help facilitators visually } \\
\text { determine top priority areas: count up } \\
\text { number of stickers per topic. }\end{array}$ \\
\hline & $\begin{array}{l}\text { Facilitators to share top priority topics, } \\
\text { introduce to the larger group. }\end{array}$ \\
\hline 10 minutes & Introduce facilitation method of choice. \\
\hline 5 minutes & $\begin{array}{l}\text { [If you chose to split the larger group so groups } \\
\text { are more random] Split into assigned } \\
\text { groups, introduce each other. }\end{array}$ \\
\hline 45 to 60 minutes & $\begin{array}{l}\text { Work through facilitated discussion of } \\
\text { choice. }\end{array}$ \\
\hline 15 minutes & Recap of discussions. \\
\hline 15 minutes & $\begin{array}{l}\text { Next steps, how PBRN will follow-up, and } \\
\text { farewell. }\end{array}$ \\
\hline
\end{tabular}

SNOCAP, state networks of colorado ambulatory practices and partners consortium; PBRN, practice-based research networks; GIS, geographic information system.

ers, including patients, community members, public health professionals, primary care providers and staff, and SNOCAP researchers. A sample agenda of a priority setting session can be found in Table 2 .

After each prioritization process, SNOCAP staff note which members or practices were especially interested and passionate about a particular topic. These notes are later used as a starting point to reengage with members at the beginning of a proposal. Informal conversations regarding participant satisfaction in the priority setting process are regularly conducted. Changes in facilitation methods have been made from over the past 5 years to address concerns that arise in these conversations.

\section{Results}

Engaging stakeholders early and often has been key in maintaining interest and relevance at the practice 
Table 3. Priority Topics and Resulting Projects at SNOCAP Priority Setting Sessions 2014 to 2018

\begin{tabular}{|c|c|c|c|}
\hline Year & Priority Discussed & Topic-Based Projects & Funder (If Applicable) \\
\hline \multirow[t]{2}{*}{2014} & Chronic Pain and Opioids & $\begin{array}{l}\text { Implementing Technology and Medication Assisted } \\
\text { Treatment Team Training in Rural Colorado } \\
\text { (IT MATTTRs)* }\end{array}$ & $\begin{array}{l}\text { Agency for Healthcare Research } \\
\text { and Quality - Peer Assist }\end{array}$ \\
\hline & & $\begin{array}{l}\text { BACKROADS, } \dagger \text { effective strategies for Medication } \\
\text { Assisted Treatment for Opioid Use Disorder in } \\
\text { rural practices }\end{array}$ & Actively seeking funding \\
\hline \multirow[t]{2}{*}{2015} & Mental Health and the Judicial & Enabling Caring Communities† & Actively seeking funding \\
\hline & System & $\begin{array}{l}\text { Implementing Medication Assisted Treatment for } \\
\text { Opioid Use Disorder in county jails* }{ }^{*}\end{array}$ & Actively seeking funding \\
\hline \multirow[t]{2}{*}{2016} & $\begin{array}{l}\text { Diabetes, Obesity, and Mental } \\
\text { Health }\end{array}$ & $\begin{array}{l}\text { Diabetes, Obesity, and Mental Health Services } \\
\text { Access Card Study (DOGMA)* }\end{array}$ & No funding required \\
\hline & & $\begin{array}{l}\text { Boot Camp Translation Check Your Sugar Check } \\
\text { Your Mood, Diabetes and Depression } †\end{array}$ & Actively seeking funding \\
\hline \multirow[t]{8}{*}{2017} & $\begin{array}{l}\text { Adult Behavioral Health } \\
\text { Access }\end{array}$ & N/A & N/A \\
\hline & $\begin{array}{l}\text { Adolescent Behavioral Health } \\
\text { Access }\end{array}$ & $\begin{array}{l}\text { UPSTREAM! Together, preventing Mental, } \\
\text { Emotional, and Behavioral issues in youth }\end{array}$ & Colorado Health Foundation \\
\hline & & Pediatric Mental Health Navigator Study $\dagger$ & Actively seeking funding \\
\hline & Chronic Pain & $\begin{array}{l}\text { Appreciative Inquiry/Boot Camp Translation (AI/ } \\
\text { BCT) }\end{array}$ & $\begin{array}{l}\text { Patient Centered Outcomes } \\
\text { Research Institute }\end{array}$ \\
\hline & Staff Burnout & Burnout Card Study (2018)* & No funding required \\
\hline & $\begin{array}{l}\text { Physical Activity/Built } \\
\text { Environment }\end{array}$ & N/A & N/A \\
\hline & Dementia & $\begin{array}{l}\text { The Engaging Communities of Hispanics for } \\
\text { Aging Research (ECHAR) Network }\end{array}$ & Proposal pending \\
\hline & Health Equity & $\begin{array}{l}\text { Improving Health by Engaging Refugees in Denver } \\
\text { (I-HEaRD) } \dagger\end{array}$ & $\begin{array}{l}\text { Patient Centered Outcomes } \\
\text { Research Institute }\end{array}$ \\
\hline \multirow[t]{4}{*}{2018} & Cost of Living/Poverty & N/A & N/A \\
\hline & Social Isolation/Loneliness & Loneliness in Rural Colorado* & $\begin{array}{l}\text { Colorado Clinical and } \\
\text { Translational Sciences } \\
\text { Institute }\end{array}$ \\
\hline & & Loneliness in Primary Care Providers* ${ }^{*}$ & Actively seeking funding \\
\hline & Primary Care Team Burnout & Primary Care Clinic Burnout Card Study* & No funding required \\
\hline
\end{tabular}

*Project was a direct result of priority setting session.

†Actively seeking funding.

SNOCAP, state networks of colorado ambulatory practices and partners consortium; N/A, not applicable.

and community level. This process has gone through multiple iterations over the past 5 years with SNOCAP leaders, practice members, patients, and communities. These processes have helped to determine topics that are truly meaningful and important to PBRN practices in Colorado. It gives a baseline for the current state of need and a point of reference for where to focus grant-writing efforts. Each iteration of the priority setting process has received positive feedback in formal conference evaluations and is shown to be a good mechanism for early detection of hot topics.

As discussed in the Methods section above, multiple methodologies have been trialed over the past 5 years to determine a process that works for setting priorities within a PBRN setting. These methods are summarized in Table 1 . After many years of leading such sessions, SNOCAP has developed a strong skeleton agenda to help guide the process, as shown in Table 2. Table 3 includes a list of each year's priority topics, resulting projects, and funders, where applicable. The process of setting priorities has resulted in studies with a mixture of observational and intervention designs supported through a variety of funding mechanisms. Note that often the first step in moving forward with a priority topic has been to start with a card study. This is an easy and inexpensive way to quickly determine the incidence and prevalence of the issue in practices. ${ }^{19}$

After reviewing 5 years of evaluation data and reflecting on conversations over the years, SNOCAP has identified 5 issues that may impact success: (1) identified priorities do not necessarily 
align with available funding opportunities; (2) there is often lag time between identifying a topic and starting a project on that topic, especially if the project requires immediate funding to move forward; (3) the length of time to get research underway may dishearten PBRN members, especially if this issue is not discussed clearly at the outset; (4) there are instances where a topic arises that is of great importance to SNOCAP members but does not align well with funders' current priorities; in these cases, topics have been delayed in initiation or have been mired in resubmission cycles due to the mismatch with funding areas; and, lastly, (5) researchers with the interest or expertise in a particular area can not always be identified or may lack interest or expertise in PBRN work.

\section{Discussion}

SNOCAP has many years of success with including research derived from priority setting conversations into the network research portfolio. Incorporating practice, patient, and community perspectives in the preproject phase gives relevance to the research brought forward from SNOCAP. Experience shows that devoting time each year to this exercise is valuable. As SNOCAP strives for grassroots organization, the focus of setting priorities cannot be at just the practice or community level; a balance between the two is needed. SNOCAP's approach to prioritization in a PBRN setting shares many similar aspects with other prioritization methods used when establishing health priorities with multiple stakeholder groups in community settings. ${ }^{20,21}$ A well-planned and facilitated process on a limited number of topics with assigned researcher-champions may lead to meaningful progress on practice- and community-relevant research.

SNOCAP has 3 recommendations to share with other PBRNs undertaking a prioritization process: (1) it is important to have trained and skilled facilitators to ensure productive discussions, as conversations can turn passionate, personal, or heated; while this is a positive outcome and can serve as a guide post that you are on the right track and reveal where true passions lie, a trained facilitator is crucial to navigate and focus these conversations; (2) PBRNs should take on a limited number of topics each year and no more than three are suggested; when additional topics are added, it is increasingly difficult to ensure they will be all be addressed and moved forward as a PBRN project; and, lastly, (3) be sure to designate a lead researcher, as well as practice champion or PBRN advisory group, for each selected topic to ensure accountability and maintain momentum.

Methods for gathering input from practices to determine topics of interest vary. Gathering responses can be difficult, as practices are often challenged with high-volume patient panels and short visit time driven by pressures from current reimbursement models. ${ }^{22}$ Time outside of reimbursable visits is a precious commodity. In addition, various members of practice staff may have different or conflicting priorities. Many PBRNs see the importance of determining current priorities at a local level and some have tried gathering priorities through formal surveys or during practice visits. ${ }^{23}$ SNOCAP, like many other PBRNs, has found that postal and email surveys of health care professionals are often met with low response rates. ${ }^{24}$

SNOCAP's annual priority setting process supports and sustains the partnerships required to keep PBRN networks active. Issues that are identified by stakeholders are then reported back for the following years, creating a culture of trust and accountability. SNOCAP's experience in priority setting can contribute to the conversation among PBRNs, their researchers, practices, and partners on how to maintain the relevancy of the research being conducted in PBRNs. By maintaining this relevance, ongoing engagement and participation of SNOCAP researchers, practices, and partners will have the built capacity and be sustained far into the future.

\section{Limitations}

This article provides the experience of 5 PBRNs collaborating in 1 state. Facilitators of these conversations have used only a small number of the many facilitated discussion methods available for this important dialog. In the early years, SNOCAP did not ground the priority-setting process in formal theory or evidence-based techniques. Over the past 5 years, work has been done to formalize this process and the plan is to continue to do so in the future. Topics and conversation generated at the annual conferences are unlikely to be generalizable to nonparticipating practices, as each practice across the state has its own priorities. Furthermore, although SNOCAP does outreach to all partners, ECER and SNOCAP Convocation attendees are usually highly motivated partners and 
often the "usual suspects" who are eager to participate. Lastly, although invitations to ECER and SNOCAP Convocation are sent to all 155 SNOCAP-affiliated practices, the majority of attendees are from a subset of practices that continue to participate year after year.

A final limitation not specific to SNOCAP is that literature still lacks when it comes to evaluating patient and community involvement in research priority setting. ${ }^{8,25}$ Current research methods for evaluating such work would be increasingly difficult to both fund and conduct in the SNOCAP setting, where patient and community advisory groups are woven so solidly into the entire research process. This is something SNOCAP would like to address in the future.

\section{Conclusions}

Regular inquiry into concerns of practices and their communities has to be seen as a necessary step when conducting true practice- or communitybased research. Understanding the needs at the local level not only helps determine priorities but also encourages open dialog and creates an enriched experience of PBRN members. Ideally, the processes shared, including various approaches and lessons learned, enable other PBRNs to establish research priorities, engage with network members, and report progress back to stakeholders.

We would like to first acknowledge everyone who has participated in a SNOCAP priority setting session in the past and for those who continue to be actively engaged as members or with a SNOCAP projects. We would be remiss to not thank all those who have come before us for bringing forth valuable contributions to prioritizing needs of our practices and communities, especially Ms. Linda Niebauer. We would also like to thank Ms. Elizabeth Staton for her careful review of this manuscript.

To see this article online, please go to: bttp://jabfm.org/content/ 32/5/655.full.

\section{References}

1. White KL, Williams TF, Greenberg BG. The ecology of medical care. N Engl J Med 1961;265:885-92.

2. Hickner J, Green LA. Practice-based research networks (PBRNs) in the United States: growing and still going after all these years. J Am Board Fam Med 2015;28:541-5.

3. Westfall JM, Mold J, Fagnan L. Practice-based research-"Blue Highways" on the NIH roadmap. JAMA 2007;297:403-6.

4. Dolor RJ, Campbell-Voytal K, Daly J, et al. Practice-based research network research good practices
(PRGPs): summary of recommendations. Clin Transl Sci 2015;8:638-46.

5. Mold JW, Peterson KA. Primary care practice-based research networks: working at the interface between research and quality improvement. Ann Fam Med 2005;3:12-20.

6. Mold JW, Gregory ME. Best practices research. Fam Med 2003;35:131-4.

7. Hoffmann AE, Leege EK, Plane MB, et al. Clinician and staff perspectives on participating in practicebased research (PBR): a report from the Wisconsin Research and Education Network (WREN). J Am Board Fam Med 2015;28:639-48.

8. Manafo E, Petermann L, Vandall-Walker V, MasonLai P. Patient and public engagement in priority setting: a systematic rapid review of the literature. PLoS One 2018;13:e0193579.

9. Balazs CL, Morello-Frosch R. The three R's: how community based participatory research strengthens the rigor, relevance and reach of science. Environ Justice. 2013;6.

10. Milton B, Attree P, French B, Povall S, Whitehead $M$, Popay J. The impact of community engagement on health and social outcomes: a systematic review. Community Dev J 2012;47:316-34.

11. Kilpatrick S. Multi-level rural community engagement in health. Aust J Rural Health 2009;17:39-44.

12. Michener JL, Yaggy S, Lyn M, et al. Improving the health of the community: Duke's experience with community engagement. Acad Med 2008;83: 408-13.

13. Community Catalyst. What is grassroots organizing. Available from: https://www.communitycatalyst.org/ resources/tools/copy-of-grassroots/what-is-grassrootsorganizing. Accessed May 30, 2019.

14. Westfall JM, VanVorst RF, Main DS, Herbert C. Community-based participatory research in practicebased research networks. Ann Fam Med 2006;4:8-14.

15. Westfall JM, Ingram B, Navarro D, et al. Engaging communities in education and research: PBRNs, AHEC, and CTSA. Clin Transl Sci 2012;5:250-8.

16. The World Café Community Foundation. A quick reference guide for hosting World Café. Available from: http://www.theworldcafe.com/wp-content/ uploads/2015/07/Cafe-To-Go-Revised.pdf. Published 2015. Accessed January 23, 2019.

17. Lipmanowic ZH, McCandless K. The surprising power of liberating structure: Simple rules to unleash a culture of innovation. Seattle: Liberating structures press; 2013.

18. Lipmanowic ZH, McCandless K. What, so what, now what? $\mathrm{W}^{3}$. Liberating Structures Available from: http://www.liberatingstructures.com/9-what-sowhat-now-what-w/. Accessed January 23, 1990.

19. Westfall JM, Zittleman L, Staton EW, et al. Card studies for observational research in practice. Ann Fam Med 2011;9:63-8. 
20. NETSCC, Cowan K. The James Lind Alliance guidebook. Version 8. Available from: http://www. jla.nihr.ac.uk/jla-guidebook/downloads/Version8-JLA-Guidebook-for-download-from-website. pdf. Published 2018. Accessed January 23, 2019.

21. Centers for Disease Control and Prevention. Gaining Consensus Among Stakeholders Through the Nominal Group Technique. Evaluation Briefs No. 7. 2006. Atlanta, GA: Centers for Disease Control and Prevention; 2018. Available from: https://www. cdc.gov/healthyyouth/evaluation/pdf/brief7.pdf. Accessed January 23, 2019.

22. Tai-Seale M, McGuire TG, Zhang W. Time allocation in primary care office visits. Health Serv Res 2007;42:1871-94.
23. Campbell-Voytal K, Daly JM, Nagykaldi ZJ, et al. Team science approach to developing consensus on research good practices for practice-based research networks: a case study. Clin Transl Sci 2015;8: 632-7.

24. Cho YI, Johnson TP, Vangeest JB. Enhancing surveys of health care professionals: a meta-analysis of techniques to improve response. Eval Health Prof 2013;36:382-407.

25. Madden M, Morley R. Exploring the challenge of health research priority setting in partnership: reflections on the methodology used by the James Lind Alliance Pressure Ulcer Priority Setting Partnership. Res Involv Engagem 2016;2:12. 